\title{
A Conceptual Understanding of Organizational Identity in the Social Media Environment
}

\author{
Jimmy Young
}

\begin{abstract}
Nonprofit organizations have increasingly adopted the use of social media over the last several years. This presents a myriad of challenges and opportunities in regards to organizational identity. This paper provides a conceptual understanding of identity as an entry point for nonprofit organizations to deliberate their own use of social media and the relative impact on organizational identity. A theoretical understanding of the formation of social identity situates the development of organizational identity and contextualizes the process in a manner suitable for conversation and strategic decisionmaking at the administrative level. A conceptual model is presented to illustrate the development and maintenance of organizational identity in the social media environment.
\end{abstract}

Keywords: Organizational identity, social media, strategy

Nonprofit and voluntary institutions all over the world find themselves at a crossroads during some point of their organizational lifecycle. For instance, new and rapidly changing technology creates unique challenges for administrators in which they must use creativity and innovation to adequately cope, move forward, and maintain sustainability. The rise of social media technology such as Facebook, YouTube, and Twitter, has many administrators mystified with exhilaration and trepidation as they begin to navigate this new interactive digital environment. This has particular implications for identity when thinking about how organizations change to "deal with turbulent environments and the increasing role of media" (Gioia, Schultz, \& Corley, 2000, p. 63).

The following discussion highlights theoretical concepts leading to the construct of identity, which offers particular insight on how to manage organizational identity within the environment of social media from an individual perspective. A brief review of the literature on organizational identity will also aid in constructing a conceptual understanding for nonprofit administrators to utilize when developing social media strategies. This is not meant to be a handbook on how to use social media; rather, it represents more of an interpretive process that administrators and organizational leaders can use to think critically about organizational identity in the social media environment, and how to advance with strategic decision-making at the administrative level. Understanding identity in any environment is important. Understanding organizational identity in the social media environment is critical for the success of any organizational strategy. The discussion begins with defining social media.

Social media provide a platform for networking and interacting in a way that allows individuals to become content creators rather than merely content consumers (Hopkins, 2008). Content refers (but is not limited) to the images, video, text, or information that is freely available on the Internet. Much of this information is found on Blogs, Facebook,

Jimmy Young, Ph.D., is an Assistant Professor in the Department of Social Work at the University of Nebraska-Kearney.

Copyright (c) 2013 Advances in Social Work Vol. 14 No. 2 (Fall 2013), 518-530 
Twitter, and YouTube, which also exemplify a myriad of social media technologies that are often referred to as Web 2.0 or the social media environment. Social media technology is an array of digital tools that are easy to use, inexpensive, and allow people to create and or manipulate their own photos, videos, and stories to share with others (Kanter \& Fine, 2010). Social media offer the opportunity for nonprofits to access and leverage multiple networks of individuals to increase volunteer pools, raise awareness about a specific issue, tap into a new funding stream, or develop innovative strategies to address diverse challenges.

The nonprofit and voluntary sector represents a number of diverse organizations, institutions, and agencies that serve critical aspects of society (Salamon, 1999). For example, in social welfare many agencies are classified as human service organizations because they seek to deliver human services and address human concerns (O’Connor \& Netting, 2009). The social work literature is still emerging with respect to how human service organizations use social media. A majority of scholarly social work literature to date centers on education, ethics, or advocacy (Edwards \& Hoefer, 2010; Giffords, 2009; Houghton \& Joinson, 2010; Kilpelainen, Paykkonen, \& Sankala, 2011; McNutt, 2008; McNutt \& Menon, 2008; Perron, Taylor, Glass, \& Margerum-Leys, 2010; RockinsonSzapkiw \& Walker, 2009). While the nonprofit sector in general is at the forefront in social media adoption (Barnes, 2011; Barnes \& Matteson, 2009; LaCasse, Quinn, \& Bernard, 2010), human service organizations continue to lag behind.

Research indicates that nonprofit organizations recognize the opportunities and challenges to utilize social media to assist with fundraising, volunteer recruitment, and to foster engagement and interaction with their community (Bortree \& Seltzer, 2009; Hackler \& Saxton, 2007; McNutt \& Menon, 2008; Rybalko \& Seltzer, 2010; Waters, 2007; Waters \& Jamal, 2011). Amid all the potential social media seem to offer, several questions remain. How does a nonprofit organization develop, share, manage, or maintain its identity in the social media environment? How does it manage identity when interacting with potentially limitless stakeholders? What are the implications for interacting with new communities in the social media environment? Recognizing how individual identity is developed or maintained will assist in understanding how organizational identity can be developed or maintained in the social media environment suitable to organizational strategy.

\section{Social Identity}

Identity is composed of many constructs, too many to unpack here, but nevertheless several theories illuminate how individuals develop their sense of identity. Charles Cooley (1902) hypothesized that one's self, or identity, is formalized through interaction and communication with others, also known as the looking glass self. Cooley's ideas are very similar to those of George Herbert Mead and that of Symbolic Interactionism, which explains that social interaction shapes the capacity for thought and serves as a process for individuals to learn the meanings and symbols that allow for individual thought. These thoughts, meanings, and symbols guide individuals to construct their identity and subsequent actions through an ongoing and changing interpretive process (Blumer, 1969). Although Symbolic Interactionism provides a lens for understanding identity formation 
through social interaction, it lacks the integration of environmental forces and macro structures of society (Ritzer, 2008).

Role theory offers some insight as to how identity is influenced by the social environment. The central view of Role theory is that individuals play many parts in their lives and others provide the basic scripts; however, the enactment of those scripts is uniquely one's own (Davis, 1986). This view aligns with that of Symbolic Interactionism because it stems from Mead's concept of role taking and the development of identity through social interaction (Berger \& Luckmann, 1967; Davis, 1986). Identifying the implication of the environment on role identity evolves from the work of Robert K. Merton, who observed that various roles of individuals depends upon the status they occupy within society (Davis, 1986). In other words, individuals may perform certain roles and behaviors based on their status as designated by social systems and assumed normative behaviors.

Identity formation and/or management in this micro context may not seem to offer much for a macro-oriented issue of organizational identity. However, this formation is extremely important when discussing the interplay of identity and environment (Hatch \& Schultz, 2002). Traditionally, and in the context of the theories described previously, identity construction happens through face-to-face encounters and in real time where individuals can immediately reconstruct their identity based on the perceptions of others. In the social media environment, individuals connect with each other through text, images, and video over various platforms synchronously, as well as mostly asynchronously. This digital platform means that individuals connect with one another without many of the meanings and symbols that help to guide their thoughts and actions. The challenge is that social media allows individuals to connect without a real sense of the context of the social interaction and may cause identity confusion or perhaps an identity crisis.

Michael Wesch (2009) describes this crisis as "context collapse" among individuals using the popular social media website YouTube (p. 23). The central premise here is that as individuals initially upload videos and interact online, they began to imagine thousands of people in a multiplicity of situations, as well as the possible perceptions of their own identity. In the midst of such a situation many individuals reported spending several hours transfixed on deciding what to say or how to act (Wesch, 2009). The issue here is not lack of interaction or context, but "the infinite number of contexts" (Wesch, 2009, p. 23). The impossibility of reshaping one's identity in that context creates a barrier for social media users that requires a sense of introspection as to how they will actually portray themselves and their identity in the social media environment. The challenge for organizational identities that continually evolve through the years, just as individual identities do, is that the invention of a new environment, specifically social media, has tremendous implications for the use and implementation of a social media strategy that seeks to encourage interaction without the context, symbols, and meanings that have come to shape and reshape the organization's identity.

Individuals have the capacity to evolve their identity in the moment and with certain immediacy. Nonprofit organizations are not always afforded the same opportunity 
because their identity may be so embedded in organizational culture, tradition, or in tangible artifacts such as a mission statement (Hatch \& Schultz, 2002). This presents a sort of organizational identity crisis. This means that if an organization that is using social media is not cognizant of this new landscape and how to perform within it, the identity or image of the organization could possibly transform into something less than ideal, at least online. Just as individuals face context collapse in the digital environment (Wesch, 2009), nonprofit organizations may also face context collapse because of the potential to access multiple new networks in a variety of different contexts without the constraint of time.

Symbolic Interactionists are generally critical of focusing on macro structures, although Blumer (1969) argues that large-scale structures emerge from micro processes. This is important for nonprofit administrators to understand because the core of social media is about interaction. Understanding how identity develops through micro-social interactions will ensure that nonprofit organizations are portraying the identity that is important to them in a new and dynamic environment (Hatch \& Schultz, 2002). Navigating the social media environment is challenging and several studies highlight how organizations are not using these new tools to their full potential of fostering interaction and engagement (Bortree \& Seltzer, 2009; Rybalko \& Seltzer, 2010; Waters \& Jamal, 2011). This may be evidenced by the context collapse discussed previously. Others, however, explain that social media users should choose their applications carefully, ensure that the applications align with the activities being selected, plan for integration, and to be social (Kaplan \& Haenlein, 2010). Kietzman, Hermkens, McCarthy, and Silvestre (2011) also explain that users should be cognizant of the available social media tools and how they align with organizational goals.

The incorporation of a social media strategy parallels the social purpose of what many nonprofit organizations do-namely, generate social capital and build community (Shafritz, Ott, \& Lang, 2005). The adoption of social media necessitates a careful review of the organization's identity prior to the implementation of the social media strategy. A brief review of the organizational identity literature further contextualizes the concept of identity development in the social media environment and provides a foundation for the necessary introspection, conversation, and development of a social media strategy.

\section{Organizational Identity}

The organizational literature defines identity as that which is central, enduring, and distinctive about an organization (Brilliant \& Young, 2004; Gioia et al., 2000; Hatch \& Schultz, 2002; Young, 2001). Brilliant and Young (2004) contend that identity is important when organizations face a diversity of challenges, such as mission completion, rapid expansion, or mergers and acquisitions that force an organization to undergo some sort of change. Organizations often must adapt their identities to address new environments and challenges (Brilliant \& Young, 2004; Sosin, 2012; Young, 2001), in addition to the flux of technology while confronting change.

The literature makes a distinction between identity and image; whereas identity is internally constructed, image involves the concept of how individuals within the 
organization think people outside of the organization perceive it (Young, 2001). This is generally important given the theoretical ideas of Cooley, Mead, and Blumer discussed previously, and specifically because this impacts how organizational members use social media to portray the organizational identity or image. Gioia and colleagues (2000) argue that this latter construct of image is defined by the "organizational elites" to project an image that communicates a specific purpose, which represents features of organizational identity (p. 66). Maintaining a positive identity in the face of changing contexts or environments, organizations must recognize that identity and image are dynamic constructs that create a paradox of continuity and change through which "instability fosters adaptability” (Gioia et al., 2000, p. 79).

The key struggle within this paradox may stem from the fact that organizations have and maintain multiple identities. Just as individuals shape their own identity based on the context of social interaction and ultimately the construction of many identities, organizations also have multiple identities because of the roles and demands from various constituencies or institutional arrangements (Brilliant \& Young, 2004; Gioia et al., 2000; Sosin, 2012). Multiple identities are beneficial for organizations in dealing with conflicting pressures of their environment as they can be analyzed and managed to the benefit of the organization (Brilliant \& Young, 2004; Sosin, 2012). However, others argue that maintaining multiple identities is paralyzing and unstable as organizations attempt the balancing act of changing their identity and keeping it the same (Gioia et al., 2000; Young, 2001). This paradox corresponds to the idea of context collapse in individuals described by Wesch (2009), and the emergence of organizational identity in the social media environment.

The concept of organizational identity has practical significance for how nonprofit organizations reinvent themselves in the face of changing environments (Brilliant \& Young, 2004). The discussion of identity development from the personal to the organizational level is intended to illustrate how identity development is fluid, dynamic, and socially constructed. This knowledge can help organizational leaders in framing their strategic use of social media to assist with organizational identity, development, and maintenance in the social media environment. Utilizing a conceptual model or enacting some general policies will also provide nonprofits with a framework for utilizing social media in a more strategic and meaningful way.

\section{A Conceptual Framework for the Strategic use of Social Media}

The Pew Internet \& American Life Project indicates that 75\% of American adults are active in some kind of voluntary group or organization and that internet users are more likely than others to be active in those organizations (Rainie, Purcell, \& Smith, 2011). Despite this unique opportunity, nonprofit organizations have been slow to capitalize on the potential of using the Internet (Sargeant, West, \& Jay, 2007). The explosion of social media use in the nonprofit sector presents clear opportunities and challenges as many administrators look to this technology as a figurative super hero coming to the rescue in an increasingly competitive and changing sector. The ability to access millions of people through Facebook, Twitter, or YouTube to increase membership, raise awareness, or increase general exposure of the organization is extremely attractive and daunting. 
Three main concepts should help nonprofit organizations that currently use or are thinking about using social media within their organization (see Figure 1). The first two concepts for using social media in a nonprofit organization are very similar, and yet distinct. Transparency and accountability have been part of the nonprofit sector for decades and ultimately work with the third concept, authenticity, to help nonprofit organizations develop and manage the organization's online identity. Although the model consists of three main concepts, the core element in the proper use of social media is interaction. Social media is mainly about making connections and having a conversation, which helps to build community. A better understanding of these concepts can orient strategic decision-making and provide the foundation for the development of a social media strategy. The conceptual model builds upon the discussion of organizational identity to help organizational leaders understand how to demonstrate their organization's distinctive elements, values, and goals in the social media environment.

Figure 1. Conceptual Model of Organizational Identity in the Social Media Environment

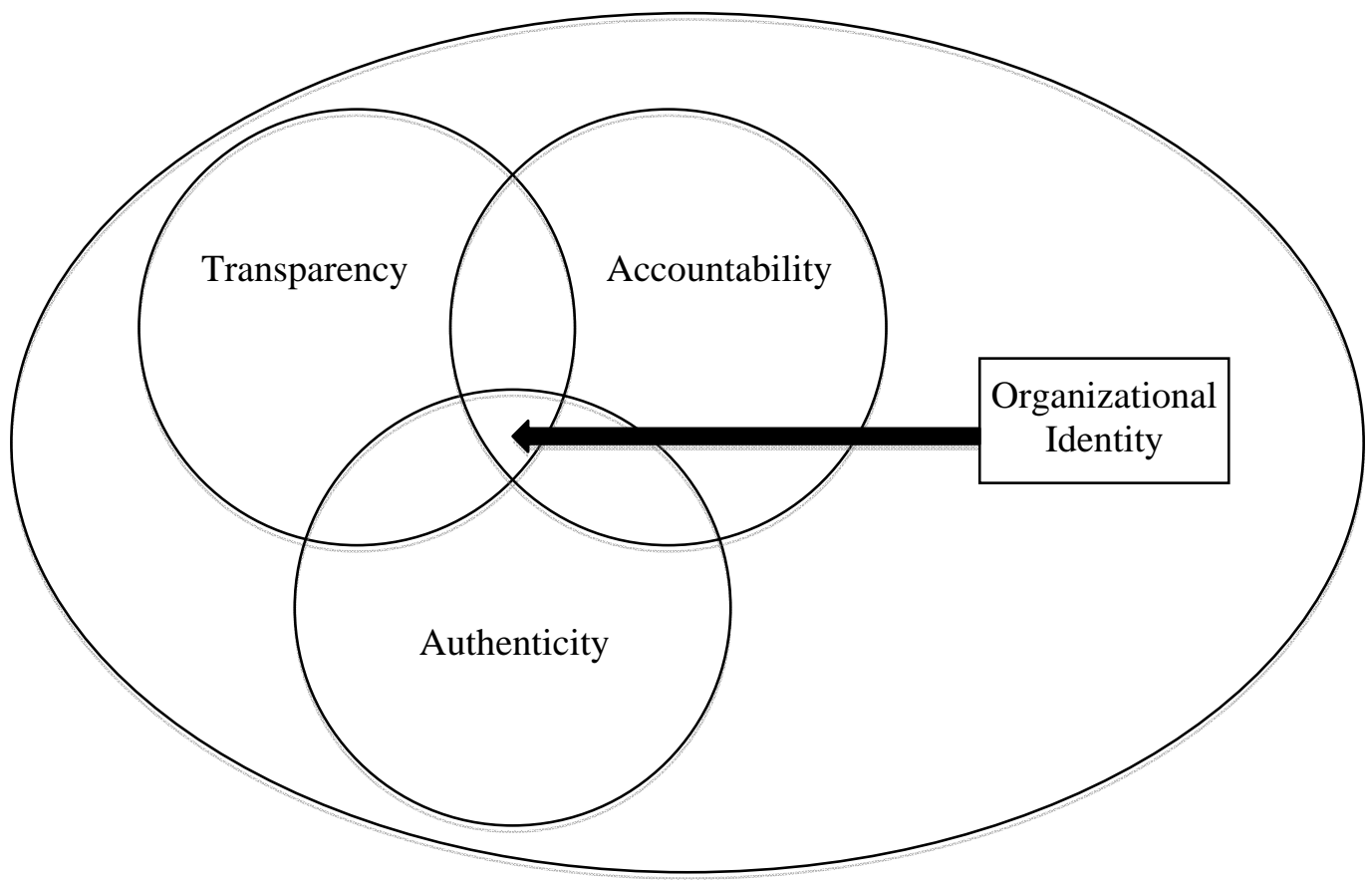

Transparency

Transparency is an evolving term with many definitions that convey how organizations are expected to operate (Ball, 2009). This discussion defines transparency as "the process of keeping actions and the decision-making processes open and available to the scrutiny of the public and the media” (Netting, Kettner, McMurtry, \& Thomas, 2012, p. 358). Nonprofit organizations are unique operations that generally lend themselves well to being transparent. Additionally, their tax-exempt status usually impels them by a legal, ethical or moral mandate to be transparent about their finances and 
operations (Jeavons, 2005). The idea of transparency or openness is not a new concept in the nonprofit sector; however, with the tools of social media that allow for rapid communication and connectivity, there is a new charge for this type of ethical behavior (Saxton \& Guo, 2011; Waters, Burnett, Lamm, \& Lucas, 2009).

Utilizing social media often means working with a networked mindset, which is characterized by principles of openness, transparency, decentralized decision-making, and distributed action (Scearce, Kasper \& Grant, 2009). Social media tools allow organizations to utilize these principles and portray to the public just how funds are used, decisions are made, and volunteer time is executed. Examples of how organizations use social media to promote these principles include organizations like Kiva (www.kiva.org) and DonorsChoose.org (www.donorschoose.org). These organizations employ the principles of social media through peer-to-peer philanthropy that allow individuals to choose and donate to specific projects. These organizations use video, images, and blogs to report on the progress of the projects, and individuals can continue to interact online by commenting and sharing with others in their own social networks by linking to the websites.

Nonprofit organizations using social media need to understand that transparency is good, but that there are also levels to transparency that should and should not be shared (Kanter, 2009). Generally, public information makes for content that is readily available for reporting on an organization's website. However, there are instances where information must remain private so as to ensure a safe place for individuals to have

discussions without disrespecting others (Kanter, 2009). Effective nonprofit organizations will assess and evaluate their work in an open and transparent process with the board and the public (Brown, 2002). This has been operationalized through websites but can now be greatly enhanced with social media and the use of networks (Saxton \& Guo, 2011; Saxton, Guo, \& Brown, 2007). Transparency is the ideal for nonprofit organizations and lends itself well to social media. This process also impacts accountability.

\section{Accountability}

Accountability, like transparency, has multiple definitions in the literature. Accountability suggests responsibility for actions and is often linked to financially related information and performance (Benjamin, 2008; Brinkerhoff, 2001; Murry, 2005; Saxton, Kuo, \& Ho, 2012). Some have argued that greater accountability interferes with the independence that gives the nonprofit sector its uniqueness (Salamon, 1999). However, grantors, the federal government, and increasingly the public are requesting greater accountability among nonprofit organizations (Binder, 2007; Brinkerhoff, 2001; Ebaugh, Chafetz, \& Pipes, 2005; Saxton \& Guo, 2011). Using social media allows organizations to demonstrate transparency and accountability through social interaction. Examples include the use of video, blogs, and most notably websites like Facebook where organizations update their status or post news on a variety of topics and actions. Specifically, nonprofit organizations are able to disclose financial records such as IRS Form-990 and other financially related performance documents (Gandia, 2011). 
Utilizing this new medium also allows a nonprofit organization to connect stakeholders to its mission and expand its targeting efforts, thereby increasing public trust and accountability (Saxton \& Guo, 2011; Saxton et al., 2007). One of the main recommendations for nonprofit organizations is to implement more content and opportunities for interaction (Gandia, 2011; Sargeant et al., 2007; Saxton et al., 2007). Accountability is more evident on the peer-to-peer philanthropy websites. As mentioned previously, these organizations employ social media to highlight the good work and causes that garner donations from people who care about the issues and the organizations.

Accountability is vital in this era of website fundraising and organizations that understand this element will do well (Sargeant et al., 2007). Social media allows nonprofit organizations to develop a relationship with individuals, or an e-relationship, and requires nonprofit organizations to view donors as partners in the process of mission achievement (Sargeant et al., 2007). Additional key components include designing websites with a focus on engagement rather than a static webpage with a simple "donate here" link, making the process of giving simple and providing a clear explanation of how the donation is being used (Ingenhoff \& Koelling, 2009; Sargeant et al., 2007). Social media tools enhance these ideas by cultivating connections as demonstrated by organizations such as Kiva, DonorsChoose.org, and many others. Examples of cultivating connections include blogging about events, posting videos through YouTube of projects that were funded by donors, and updating the organization's status on Facebook or Twitter to advertise the work that is being done (Waters et al., 2009; Waters \& Jamal, 2011).

Transparency and accountability are important elements for nonprofit organizations to embrace in general. They are particularly important when using social media if the organization hopes to see engagement from various stakeholders and earn the trust of all supporters (Ingenhoff \& Koelling, 2009; Ingram, 2009; Saxton \& Guo, 2011). Transparency and accountability naturally flow into the final principle of this framework and help to establish authenticity.

\section{Authenticity}

In the absence of symbols and meanings that help to form identity, and facing context collapse because of the endless possibilities, individuals are left to make a connection with a source deep within themselves as they are free to decide who they are (Taylor, 1992). Authenticity is to be true to one's self and is a construct that develops along with identity; however, Taylor (1992) argues that this construct has lost meaning in contemporary culture as it has come to focus more on modes of self-fulfillment and less on strengthening ties to community. Authenticity in the social media environment is about staying true to the organizational identity as well as strengthening ties to its community. Authenticity is about relationships; it is what keeps people engaged and willing to spread the word about a particular service, message, or cause through their own social networks.

Amid the many professional blogs and articles professing details or guidelines on how to make a nonprofit organization successful in the social media environment, 
portraying a caring image is truly what will make an organization successful. However, it is more than just portraying a specific identity, it is demonstrating transparency and accountability in an authentic and genuine manner that builds trust, respect, and cohesion among the social networks of individuals who come into contact with the organization via their friends or families through social media. Saxton and Guo (2011) believe that this new medium offers great potential for nonprofit organizations to be more responsive to their core constituents. Responsiveness, interaction, and participation help to increase authenticity, transparency, and accountability.

It is critical for nonprofit organizations to understand that their identity develops based on interactions, just as it does for individuals. Despite the multiplicity of contexts, organizations must realize that being authentic will allow for their true identity to come forth, and they should not be afraid to demonstrate that. Social media is merely a mechanism to create unique connections, and if nonprofit organizations do not take the time to critically think about their social media identities, they will face challenges and frustration.

Kanter and Fine (2010) discuss this idea as the concept of developing a social culture, or a culture where the organization uses the power of social media to change relationships. The shift to a social culture requires organizations to become more open and transparent, and to devote critical attention to authentic conversations (Kanter \& Fine, 2010). Authenticity exists when organizations leverage the power of social media to develop relationships, build trust, listen, and respond to the community. Using this framework as guide, nonprofit organizations can begin to think about various strategies and methods as they implement the use of social media.

\section{Conclusion}

Nonprofit organizations that recognize their organizational identity and the need to develop or maintain the identity in multiple contexts will be better off in their pursuits of social media because they can be flexible and make strategic decisions. Recognizing that identity is socially constructed is the first step to understanding organizational identity. Secondly, identity formation is fluid and dynamic based on the effects of social interactions and the environment (Gioia et al., 2000; Hatch \& Schultz, 2002).

The most challenging factor in using social media may not merely be organizational identity maintenance, but the notion that organizations must give up some sense of control to the community of users (Watson, 2009). Nonprofit organizations that are transparent, accountable, and authentic should not have issues with this sense of letting their social media community actively participate in the conversation. After all, the core of social media is connecting and having a conversation that builds trust, engagement, and ultimately community. This opportunity to collaborate with the social media community, combined with an understanding of organizational identity development and the conceptual framework outlined above, provides the initial foundation for thinking strategically about using social media within the organization. 


\section{References}

Ball, C. (2009). What is transparency? Public Integrity, 11(4), 293-307. doi: 10.2753/ PIN1099-9922110400

Barnes, N. G. (2011). Social Media Usage Now Ubiquitous Among US Top Charities, Ahead of All Other Sectors. Retrieved from http://www.umassd.edu/cmr/studiesandresearch/socialmediatopcharities/

Barnes, N. G., \& Mattson, E. (2009). US Charities’ Adoption of Social Media Outpaces All Other Sectors for the Third Year in a Row. Retrieved from http://www.fcae.umassd.edu/cmr/studiesresearch/charitystudy.cfm

Benjamin, L. M. (2008). Account space: How accountability requirements shape nonprofit practice. Nonprofit and Voluntary Sector Quarterly, 37(2), 201-223. doi: 10.1177/0899764007301288

Berger, P. L., \& Luckmann, T. (1967). The social construction of reality. New York, NY: Doubleday.

Binder, A. (2007). For love and money: Organizations' creative responses to multiple environmental logics. Theory \& Society, 36(6), 547-571.

Blumer, H. (1969). Symbolic interactionism: Perspective and method. Berkeley, CA: University of California Press.

Bortree, \& Seltzer, T. (2009). Dialogic strategies and outcomes: An analysis of environmental advocacy groups’ Facebook profiles. Public Relations Review, 35(3), 317-319.

Brilliant, E., \& Young, D. R. (2004). The changing identity of federated community service organizations. Administration in Social Work, 48(3/4), 23-46.

Brinkerhoff, D. W. (2001). Taking account of accountability: A conceptual overview and strategic options. Washington, DC: US Agency for International Development.

Brown, W. A. (2002). Inclusive governance practices in nonprofit organizations and implications for practice. Nonprofit Management \& Leadership, 12(4), 369-385.

Cooley, C. H. (1902). Human nature and the social order. New York, NY: Charles Scribner's Sons.

Davis, L. V. (1986). Role theory. In F. J. Turner (Ed.), Social work treatment: Interlocking theoretical approaches ( $3^{\text {rd }}$ ed., pp. 541-563). New York, NY: The Free Press.

Ebaugh, H. R., Chafetz, J. S., \& Pipes, P. (2005). Funding good works: Funding sources of faith-based social service coalitions. Nonprofit and Voluntary Sector Quarterly, 34(4), 448- 472.

Edwards, H. R., \& Hoefer, R. (2010). Are social work advocacy groups using web 2.0 effectively? Journal of Policy Practice, 9(3-4), 220-239. doi: 10.1080/15588742. 2010.489037 
Gandia, J. L. (2011). Internet disclosure by nonprofit organizations: Empirical evidence of nongovernmental organizations for development in Spain. Nonprofit and Voluntary Sector Quarterly, 40(1), 57-78. doi: 10.1177/089976009343782

Giffords, E. D. (2009). The Internet and social work: The next generation. Families in Society: The Journal of Contemporary Social Services, 90(4), 413-418. doi: 10.1606/1044-3894.3920

Gioia, D. A., Schultz, M., \& Corely, K. G. (2000). Organizational identity, image, and adaptive instability. Academy of Management Review, 25(1), 63-81.

Hackler, D., \& Saxton, G. (2007). The strategic use of information technology by nonprofit organizations: Increasing capacity and untapped potential. Public Administration Review, 67(3), 474-484.

Hatch, M. J., \& Schultz, M. (2002). The dynamics of organizational identity. Human Relations, 55(8), 989-1018.

Hopkins, M. (2008). Just what is social media, exactly? Retrieved from http://mashable.com/2008/11/18/social-media-defined/

Houghton, D. J., \& Joinson, A. N. (2010). Privacy, social network sites, and social relations. The Journal of Technology in Human Services, 28, 74-94. doi: 10.1080/15228831003770775

Ingenhoff, D., \& Koelling, A. M. (2009). The potential of web sites as a relationship building tool for charitable fundraising NPOs. Public Relations Review, 35, 66-73. doi:10.1016/j.pubrev.2008.09.023

Ingram, R. T. (2009). Ten basic responsibilities of nonprofit boards $\left(2^{\text {nd }}\right.$ ed.). Washington, DC: Boardsource.

Jeavons, T. H. (2005). Ethical management. In R. D. Herman \& Associates (Eds.), The Jossey-Bass handbook of nonprofit leadership \& management ( $2^{\text {nd }}$ ed., pp. 204-229). San Francisco, CA: Jossey-Bass.

Kanter, B. (2009, August 8). Transparency camp west 09: Blogging and tweeting an open board meeting. Retrieved from http://beth.typepad.com/beths_blog/

Kanter, B., \& Fine, A. H. (2010). The networked nonprofit: Connecting with social media to drive change. San Francisco, CA: Jossey-Bass.

Kaplan, A. M., \& Haenlein, M. (2010). Users of the world, unite! The challenges and opportunities of Social Media. Business Horizons, 53, 59-68.

Kietzman, J. H., Hermkens, K., McCarthy, I. P., \& Silvestre, B. S. (2011). Social media? Get serious! Understanding functional building blocks of social media. Business Horizons, 54, 241-251. doi: 0.1016/j.bushor.2011.01.00

Kilpelainen, A., Paykkonen, K., \& Sankala, J. (2011). The use of social media to improve social work education in remote areas. The Journal of Technology in Human Services, 29(1), 1-12. doi: 10.1080/15228835.2011.572609 
LaCasse, K., Quinn, L. S., \& Bernard, C. (2010). Using social media to meet nonprofit goals: The results of a survey. Portland, ME: Idealware.

McNutt, J. G. (2008). Web 2.0 tools for policy research and advocacy. Journal of Policy Practice, 7(1), 81-85. doi: 10.1080/15588740801909994

McNutt, J. G., \& Menon, G. M. (2008). The rise of cyberactivism: Implications for the future of advocacy in the human services. Families in Society: The Journal of Contemporary Social Services, 89(1), 33-38. doi: 10.1606/1044-3894.3706

Murry, V. (2005). Evaluating the effectiveness of nonprofit organizations. In R. D. Herman \& Associates (Eds.), The Jossey-Bass handbook of nonprofit leadership \& management ( $2^{\text {nd }}$ ed., pp. 81-101). San Francisco, CA: Jossey-Bass.

Netting, F. E., Kettner, P. M., McMurtry, S. L., \& Thomas, M. L. (2012). Social Work Macro Practice ( $5^{\text {th }}$ ed.). Upper Saddle River, NJ: Pearson.

O’Connor, M. K., \& Netting, F. E. (2009). Organization practice: A social worker's guide to understanding human services. Hoboken, NJ: John Wiley \& Sons, Inc.

Perron, B. E., Taylor, H. O., Glass, J. E., \& Margerum-Leys, J. (2010). Information and communication technologies in social work. Advances in Social Work, 11(1), 67-81.

Rainie, L., Purcell, K., \& Smith, A. (2011). Social side of the Internet. Pew Internet \& American Life Project. Retrieved from http://www.pewinternet.org/Reports/2011/The-Social-Side-of-the-Internet.aspx

Ritzer, G. (2008). Modern sociological theory ( $7^{\text {th }}$ ed.). New York, NY: McGraw-Hill.

Rockinson-Szapkiw, A. J., \& Walker, V. L. (2009). Web 2.0 technologies: Facilitating interaction in an online human services counseling skills course. The Journal of Technology in Human Services, 27, 175-193. doi: 10.1080/15228830903093031

Rybalko, S., \& Seltzer, T. (2010). Dialogic communication in 140 characters or less: How Fortune 500 companies engage stakeholders using Twitter. Public Relations Review, 36(4), 336-341. doi: 10.1016/j.pubrev.2010.08.004

Salamon, L. M. (1999). America's nonprofit sector: A primer $\left(2^{\text {nd }}\right.$ ed.). New York, NY: The Foundation Center.

Sargeant, A., West, D. C., \& Jay, E. (2007). The relational determinants of nonprofit web site fundraising effectiveness: An exploratory study. Nonprofit Management \& Leadership, 18(2), 141-156.

Saxton, G. D., \& Guo, C. (2011). Accountability online: Understanding the web-based accountability practices of nonprofit organizations. Nonprofit and Voluntary Sector Quarterly, 40(2), 270-295. doi: 10.1177/0899764009341086

Saxton, G. D., \& Guo, C., \& Brown, W. A. (2007). New dimensions of nonprofit responsiveness: The application and promise of Internet-based technologies. Public Performance \& Management Review, 31(2), 144-173. doi 10.2753/PMR15309576310201 
Saxton, G. D., Kuo, J., \& Ho, Y. (2012). The determinants of voluntary financial disclosure by nonprofit organizations. Nonprofit and Voluntary Sector Quarterly, 41(6), 1051-1071. doi: 10.1177/0899764011427597

Scearce, D., Kasper, G., \& Grant, H. M. (2009). Working wikily 2.0: Social change with a network mindset [Electronic Version]. The Monitor Institute website. Retrieved from http://www.workingwikily.net/Working_Wikily_2.0.pdf

Shafritz, J. M., Ott, J. S., \& Lang, Y. S. (2005). Classics of organization theory (6 $6^{\text {th }} \mathrm{ed}$.). Belmont, CA: Thomson Wadsworth.

Sosin, M. R. (2012). Social expectations, constraints, and their effect on nonprofit strategies. Nonprofit and Voluntary Sector Quarterly, 41(6), 1231-1250. doi: 10.1177/0899764011431830

Taylor, C. (1992). The ethics of authenticity. Cambridge, MA: Harvard University Press.

Waters, R. D. (2007). Nonprofit organizations' use of the Internet: A content analysis of communication trends on the Internet sites of the Philanthropy 400. Nonprofit Management \& Leadership, 18(1), 59-76. doi: 10.1002/nml.171

Waters, R. D., Burnett, E., Lamm, A., \& Lucas, J. (2009). Engaging stakeholders through social networking: How nonprofit organizations are using Facebook. Public Relations Review, 35, 102-106.

Waters, R. D., \& Jamal, J. (2011). Tweet, tweet, tweet: A content analysis of nonprofit organizations’' Twitter updates. Public Relations Review, 37(3), 321-324. doi: 10.1016/j.pubrev.2011.03.002

Watson, T. (2009). Causewired: Plugging in, getting involved, changing the world. Hoboken, NJ: Wiley \& Son's.

Wesch, M. (2009). YouTube and you: Experiences of self-awareness in the context collapse of the recording webcam. Explorations in Media Ecology, 8(2), 19-34. Retrieved from http://hdl.handle.net/2097/6302

Young, D. R. (2001). Organizational identity and the structure of nonprofit umbrella associations. Nonprofit Management \& Leadership, 11(3), 289-304.

\section{Author note:}

Address correspondence to: Jimmy Young, Ph.D., Assistant Professor, Department of Social Work, Founders Hall, University of Nebraska-Kearney, $25049^{\text {th }}$ Avenue, Kearney, NE 68849. Email: youngja2@unk.edu 